
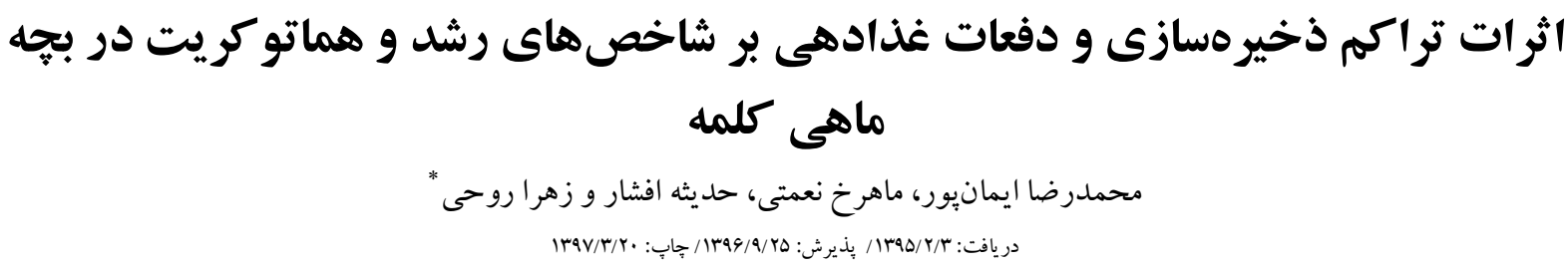

دريافت:

گروه شيلات، دانشكدة شيلات و محيط زيست، دانشكاه علوم كشاورزى و منابع طييعى گر كان، كر كان، ايران

zahra.roohi@gau.ac.ir :

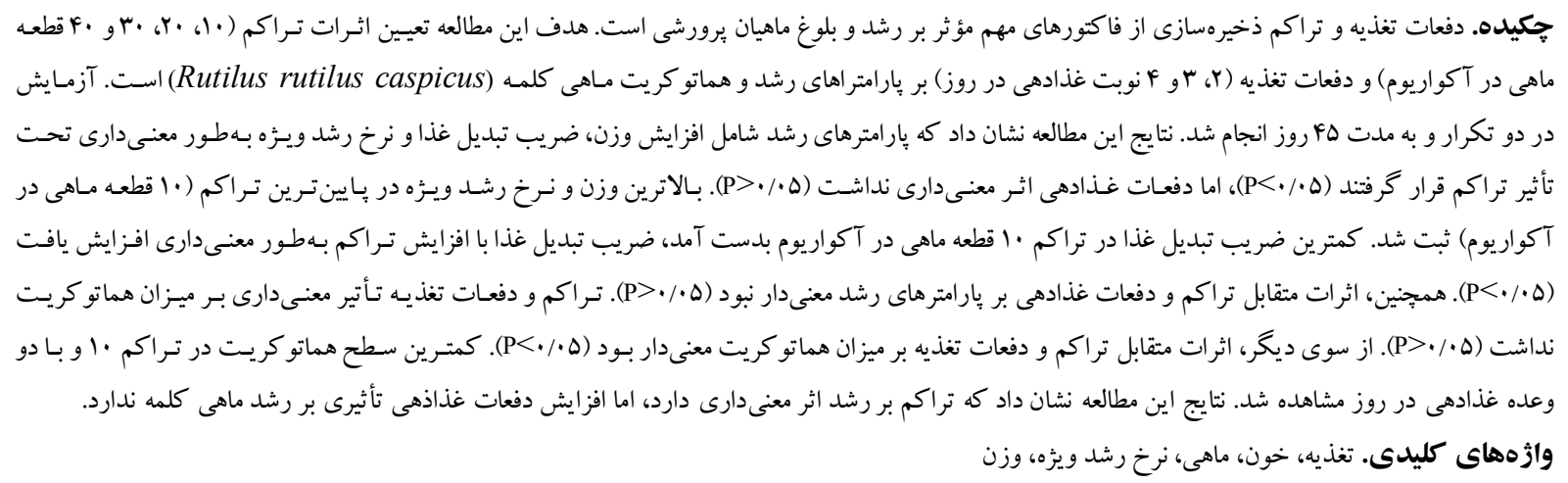

\title{
Effects of stocking density and feeding frequency on the growth
} parameters and hematocrit of the Rutilus rutilus caspicus juvenile

\author{
Mohammad Reza Imanpoor, Mahrokh Nemati, Hadiseh Afshar \& Zahra Roohi ${ }^{*}$ \\ Received 22.04.2016/ Accepted 16.12.2017/ Published 10.06.2018
}

Fisheries Sciences, Department of Fisheries and Environment, Gorgan University of Agricultural Sciences and Natural Resources, Gorgan, Iran

"Correspondent author: zahra.roohi@gau.ac.ir

Abstract. Feeding frequency and stocking density are important factors affecting growth and maturation of cultured fish. The aims of this investigation were to determine the effects of stocking density $(10,20,30$ and 40 fish per aquarium) and feeding frequency (2,3 and 4 times on daily) on growth parameters and hematocrit of the Rutilus rutilus caspicus juveniles. The experiment was continued for 45 days in two replicates. The results of this study showed that growth parameters, including weight gain (WG), feed conversion ratio (FCR) and specific growth rate (SGR) were affected significantly by stocking density $(\mathrm{P}<0.05)$, but not significantly affected by feeding frequency $(\mathrm{P}>0.05)$. The highest WG and SGR were recorded with the lowest stocking density (10 fish / aquarium). The least FCR was obtained in density of 10 fish/aquarium, FCR value was significantly higher with high stocking density $(\mathrm{P}<0.05)$. Also, interactions between stocking density and feeding frequency were no significant on growth parameters $(\mathrm{P}>0.05)$. Density and feeding frequency had no significant effect of hematocrit concentration $(\mathrm{P}>0.05)$. On the other hand, interactions between stocking density and feeding frequency significantly affected hematocrit levels $(\mathrm{P}<0.05)$. The lower level of hematocrit was observed in density of 10 fish/aquarium at two times / day feeding frequency. The results of this study indicated that density is significantly affected the growth, but increasing of feeding frequency there is not effect on growth in the Rutilus rutilus caspicus.

Keywords. blood, fish, nutrition, specific growth rate, weight 
دلايل مختلفى ازجمله آلودگى آبهـا، تخريـب رودخانههـا، ايجـاد

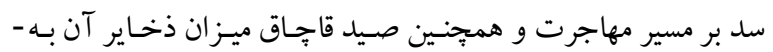

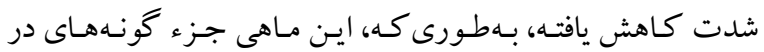

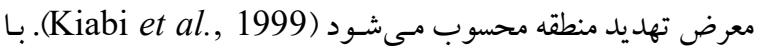

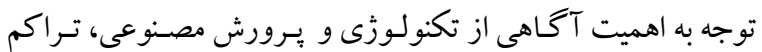



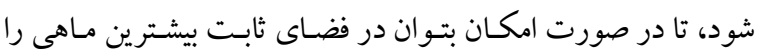

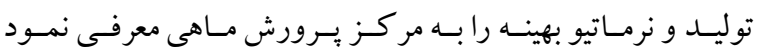

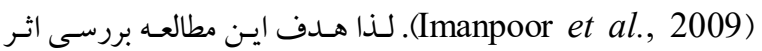

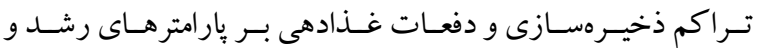
هماتو كريت بجِهماهى كلمه است.

\section{مواد و روشها}

اين يُزوهش در مركز تحقيقات آبزى يرورى شهيد فضلىبر آبادى

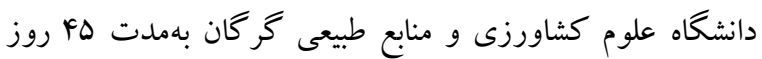



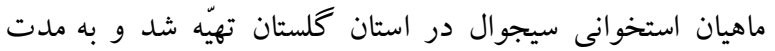



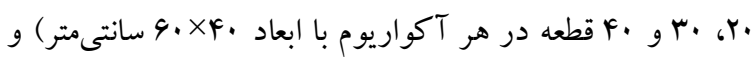

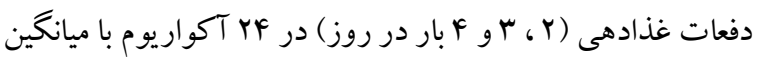

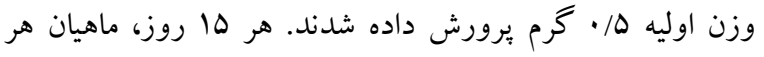
آكواريوم بيومترى و مقدار غذادهى (بيومار، فرانسه) براساس آن

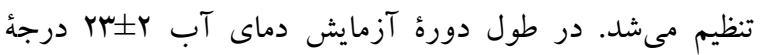

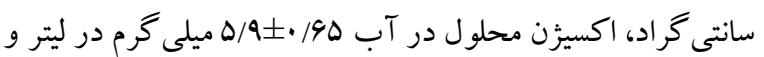



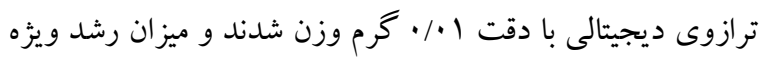
و ضريب تبديل غذا (FGR) محاسبه شد. بهمنظور تحليل هماتوكريت، · ل ماهى بهطور تصادفى صنى







.(Imanpoor \& Roohi, 2015)





FCR= (ميزان افز ايش وزن +ميزان غذا دهى)
مقلمه

تراكم ذخيرهسـازى يكى از فاكتورهـاى كليـدى در تعيـين بهـره-

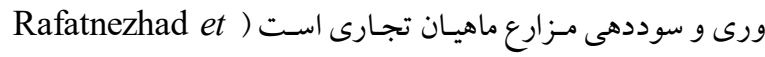
al., 2008 (al. تـراكم بـالا تكنيـك اسـتفاده حـداكثر از آب اسـت. افزايش تراكم ذخيرهسازى بسيارى از گونهها نشان مىدهــ كـه ايـن


كونسهـا تـأثير منفى داشتهـ باشــ ( Andrews \& Page, 1975;

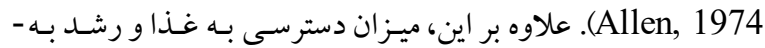

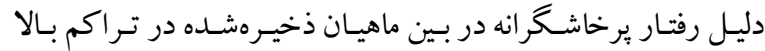

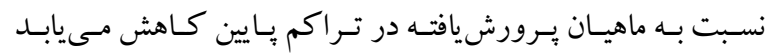
(Jobling \& Baardvik, 1994; Irwin et al., 1999) بــراى غـذا، عـاملى محدود كنتـده و مهـم در رشــــ ماهيـان اسـت و رفتارهاى رقابتى و تجمعى ماهيـان در وضسعيت كمبـود غـذا افزايش مسيابـ (Holm et al., 1990; Bayunova et al., 2002). كسـب اطلاعـات درخصـوص تعـداد دفعـهــاى تغذيـهُ مطلـوب در ماهيان براى يرورش دهند گان ماهى بسيار مهـم اسـت. تغذيـــ بـيش از حد به كاهش كيفيـت آب، افزايش بيمـارى، مـرك و ميـر ماهيـان،


1989). علاوه بر ايـن، رشـــ ماهيـان بـهـ نـوع جيـرهُ غـذايى، دفعـات غذادهى، ميزان غذاى كسبشـــه و توانـايى در جـذب مـواد مغـذى

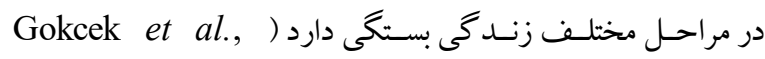

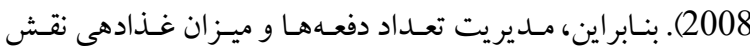
تعيين كنندهاى در تنظيم غذاى كسـبـشـده، ميـزان رشـد و ضـايعات Andrews \& Page, 1975; Chun \& Teng, ) غـادارد 1982; Ruohenen et al., 1999; Lee et al., 2000; (Dwyer et al., 2002; Wang et al., 2007 مىدهد كـه رشـد و تر كيـب شـيميايى بــن ماهيـان مسى توانـد تحـت



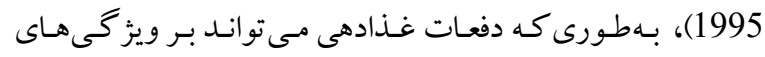

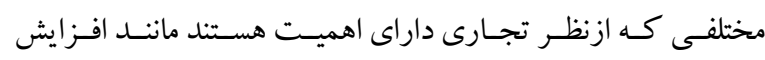
بيومـاس، رشـــ و نمـو، كـاهش نسـبت غـذا بـه افزايش وزن بـــن،

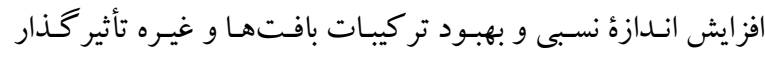

باشد (Sheare, 1994; Boujard et al., 1995$)$ مـاهى كلمـه (Rutilus caspicus ) يكسى از گونسهــاى بـومى درياى خزر با ارزش تجارى بـالا اسـت كـه در سـالهـاى اخيـر بـه - 
2000). دســكارى در برخـى فاكتورهــاى خـار جى مانــــ دفعـات غذادهى، تكنيكك غذادهى يا تراكم ماهى ممكـن اسـت تغيير اتى در وزن بدن گونهاى مختلف مـاهى بسهوجسود آورد ( McCarthy et al., 1996 ). بنابراين، تعيين روشهاى برورشى بهبـوددهنـدهُ توليـــ



در ايـن مطالعـه، يارامترهـاى آب در طـول دوره آزمـايش تفــاوت معنى دارى نشان ندادند، بنابر اين تغييرات رشد مسىتوانــ بـه تـراكم و دفعـات غـذادهى مربـوط باشـد. تــراكم يـرورش يكـى از مهـم تـرين عامل مؤثر بر نتـايج حاصـل از يسرورش ماهيـان است ( El-Saidy

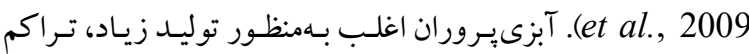
ذخيرهسـازى را افزز ايش مسىدهنــ (Iguchi et al., 2003 ). اثبـات شده است كه برورش در تراكمهاى نامناسـب ممكـن اسـت رشـد و سيستم ايمنى را كاهش دهد و بـه ايجـاد رفتارهـاى غيرطبيعى منجـر شود ) Barcellos et al., 2004; Kristiansen et al., 2004 (North et al., 2006 . بهور كلى، كاهش رشد شاخصسى مناسب براى استرس مزمن در نظر گرفته مىشود كه در گونههاى برورشى

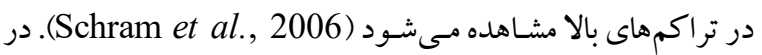


ضريب تبديل غذا كاهش يافت. بهترين نتيجه به بجهماهيانى مربـوط بود كـه بـا تـراكم · اقطعهـ مـاهى در آكواريسوم رشـد يافتـه بودنـد. نتـايج بـهدسـت آمــده بـا مطالعـات Rafatnezhad و همكــاران


Moradyan ،Hippocampu abdominalis


و همكـار ان (2013) دربـارؤ مـاهى قرمـز مطابقـت دارد. بـهمنظـور

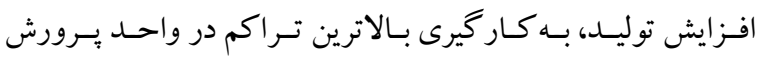
ضـرورى است (Björnsson \& Ólafsdóttir, 2006 ). يكى از يامـدهاى افز ايش تـراكم، كنـدى رشـــ اسـت كـه بـهدليـل كـاهش

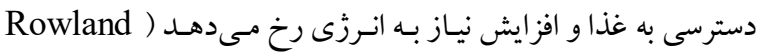
et al., 2006; Rahman et al., 2008, 2010; Rahman \&

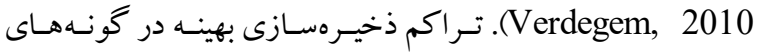
مختلـف بسـيار متفــاوت اسـت (Wallace et al., 1988) و فاكتورهـاى خـارجى مانتـــ كيفيـت آب، دمــاى آب ، كميّـت و كيفيت غذا مىتواند نتايج تراكمهاى مختلف را تحت تأثير قرار
دادههاى بهدست آمـلده بـا اسـتفاده از تحليـل واريـانس يـك طرفـه بـا نرمافزار SPSS ارزيابى شد. ارزيابى تفاوت معنى دار بين ميـانگين ها در سطح هـ/ • از طريق آزمون دانكن انجام كرفت.

نتايج نتايج تحليل واريانس وزن نهايى، ضريب تبديل غذا، هماتو كريت و ميزان رشد ويزه در جدول ا نشان داده شده است. نتايج بررسى حاضر نشان مىدهد كه تراكم ذخيرهسازى اثر معنىدارى . . . . . . بر وزن نهايى دارد، بهطورى كه با افزايش تراكم وزن نهايى كاهش معنى دارى نشان داد. بهترين وزن در تراكم · ا مشاهده شد (جدول Y). تكرار غذادهى تأثير معنىدارى بر وزن نهايى نداشت ، اثر متقابل غذادهى و تراكم ذخيرهسازى نيز تأثير معنىدارى بر رشد نداشت. تراكم ذخيرهسازى بر ميزان ضريب تبديل غذا اثر معنى دارى داشت و با افزايش تراكم ذخيرهسازى ضريب تبديل غذايى افزايش يافت (جدول r). با اينحال، دفعات غذادهى و اثر متقابل دفعات و تراكم تأثير معنىدارى بر ضريب تبديل غذايى نداشت.

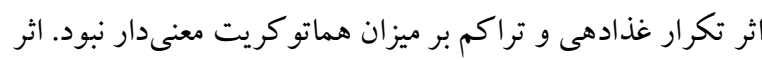
متقابل دفعات و تراكم بر ميزان هماتوكريت تأثير معنىدارى داشت، بهطورى كه با افزايش تراكم و تكرار غذادهى ميزان هماتوكريت افزايش يافت. كمترين ميزان هماتوكريت در ب بار غذادهى و تراكم ·ل بود (جدول F). تراكم ذخيرهسازى بر ميزان رشد ويزه اثر معنىدارى داشت و با افزايش تراكم ذخيرهسازى، ميزان رشد ويزه كاهش يافت (جدول ه). بهترين ميزان رشد ويزه در تراكم •ا مشاهده شد. تكرار غذادهى و اثر متقابل تكرار و و. تراكم نيز تأثير معنىدارى بر ميزان رشد ويزه نداشت. برخى

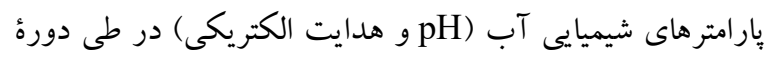
يرورشى به ترتيب در جدول 9 و V آمده است. ميزان pH و هدايت الكتريكى در بين تيمارهاى مختلف اختلاف معنىدارى نداشت. pH الكتريكى در محدودة IFIV| I99V قرار داشت.

\section{بحث و نتيجه}



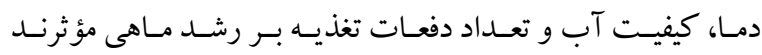
Berg et al., 1996; Baskerville-Brides \& Kling, ) 
جدول ا - نتايج تجزيه واريانس دادههاى صفات تحت بررسى در ماهى كلمه.

Table 1. Analysis of variance of traits under study in the Caspian roach.

\begin{tabular}{|c|c|c|c|c|c|}
\hline نرخ رشد ويثه & هماتوكريت & ضريب تبديل غذا & وزن نهايى & درجهُ آزادى & منبع متغير \\
\hline$\cdot / \cdot r \Lambda^{\mathrm{ns}}$ & $r / \cdot r \Lambda^{\mathrm{ns}}$ & $\cdot / \cdot \mathrm{kns}^{\mathrm{ns}}$ & $\cdot / \cdot 1^{\mathrm{ns}}$ & $r$ & دفعات غذادهى \\
\hline.$/ r V r^{*}$ & rq/VQr $\mathrm{rS}^{\mathrm{nS}}$ & $\cdot / r \Delta \Delta \Delta^{*}$ &.$/ \cdot \mu v^{*}$ & $r$ & 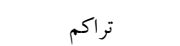 \\
\hline$\cdot(\cdot r)^{\mathrm{ns}}$ & TV/NVA & $\cdot / \cdot r \Lambda^{\mathrm{ns}}$ & $\cdot / \cdot 11^{\mathrm{ns}}$ & 4 & دفعات غذادهى× تراكم \\
\hline.$/ \Delta r$ & $\Lambda / r \Delta$ &.$/ .+F$ &.$/ .99$ & ir & خطا \\
\hline
\end{tabular}
nمs

${ }^{n s}$ and * significant and non-significant at the $5 \%$ level, respectively.

جدول r-وزن نهايى (كرم) ماهيان (ميانگين انحر اف معيار) در تراكم و دفعات غذادهى مختلف.

Table 2. Final weight (gr) of the fish (mean \pm SD) in different density and feeding times.

\begin{tabular}{|c|c|c|c|c|}
\hline F. تراكم & تراكم •r & rتراكم.r & تراكم · & متغير \\
\hline$\cdot / V q \cdot \pm \cdot / \cdot \Delta q^{b}$ & $\cdot / \Lambda V r \pm \cdot / \mid F^{a b}$ & $\cdot / q \& V \pm \cdot / / F \Lambda^{\mathrm{ab}}$ & $1 / .99 \pm \cdot / \cdot v^{a}$ & بارغذادهى \\
\hline$\cdot / \wedge r q \pm \cdot / \cdot \uparrow \cdot{ }^{b}$ & $\cdot / \wedge \& G \pm \cdot / \cdot \mid f^{b}$ & $\cdot / a q 1 \pm \cdot / \backslash \wedge \Delta^{a b}$ & $\cdot / 99 \Lambda \pm \cdot / \cdot v^{\mathrm{a}}$ & بار غذادهى \\
\hline$\cdot / \Lambda Y F \pm \cdot / \cdot V F^{b}$ & $\cdot / 919 \pm \cdot / \cdot v \Delta^{a b}$ & $\cdot / 94 \cdot \pm \cdot / \cdot \Delta \Delta^{\mathrm{ab}}$ & $1 / \cdot \wedge V \pm \cdot / \cdot r \Delta^{\mathrm{a}}$ & Fار غذادهى \\
\hline
\end{tabular}

Different letters in the same row indicate a significant difference $\mathrm{P}<0.05$.

جدول ب- تغييرات ضريب تبديل غذا (ميانكين 土 انحر اف معيار) در تراكم و دفعات غذادهى مختلف.

Table 3. Changes of feed conversion efficiency (mean \pm SD) in different density and feeding times.

\begin{tabular}{|c|c|c|c|c|}
\hline F. Fراكم & rتراكم r. & r. تراكم r. & تراكم 1. & متغير \\
\hline$r / r r \Delta \pm \cdot / \cdot r I^{a}$ & $r / \cdot r \Delta \pm \cdot / \mid F \Lambda^{\mathrm{ab}}$ & $r / \mathrm{r} \cdot \pm \cdot / \& \Lambda \cdot{ }^{b}$ & $r / \wedge q \cdot \pm \cdot /|f|^{a b}$ & سبار غذادهى \\
\hline$r / r 90 \pm \cdot / r q V^{a}$ & $r / I V \cdot \pm \cdot / \cdot \Delta q^{\mathrm{a}}$ & $r / 110 \pm \cdot / \cdot k q^{a b}$ & $r / \wedge v \cdot \pm \cdot / \cdot \wedge \mathrm{f}^{\mathrm{b}}$ & Fار غذادهى \\
\hline
\end{tabular}

جدول ع- تغيرات (ميانگين土 انحراف معيار) هماتو كريت (درصد) در تراكم و دفعات غذادهى مختلف.

Table 4. Changes (mean \pm SD) of hematocrit (\%) in different density and feeding times.



Different letters in the same row indicate a significant difference $\mathrm{P}<0.05$.

جدول 0- تغييرات نرخ رشد ويثه (ميانگين土 انحر اف معيار) در تراكم و دفعات غذادهى مختلف.

Table 5. Changes of specific growth rate (mean \pm SD) in different density and feeding times.

\begin{tabular}{|c|c|c|c|c|}
\hline F. Fراكم & تراكم ·r & تراكم ·r r & تراكم · & 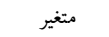 \\
\hline$. / 9 r V \pm \cdot / 190^{b}$ & $1 / r r \Delta \pm \cdot /\left.r q\right|^{a b}$ & $1 / F \cdot q \pm \cdot / \mu F \Lambda^{a b}$ & $1 / V F r \pm \cdot / I F \Delta^{a}$ & rارغذادهى \\
\hline$|/| f \mid \pm \cdot / 1 \cdot 4^{b}$ & $|/| v \mid \pm \cdot / \cdot r v^{b}$ & $|/ r \wedge F \pm \cdot / F F|^{a}$ & $1 / 499 \pm \cdot / 19 \Lambda^{\mathrm{a}}$ & سبار غذادهى \\
\hline
\end{tabular}

Different letters in the same row indicate a significant difference $(\mathrm{P}<0.05)$. 


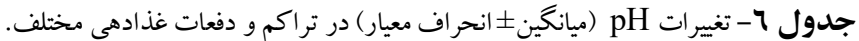

Table 6. Changes of pH (mean \pm SD) in different density and feeding times.

\begin{tabular}{|c|c|c|c|c|}
\hline F. تراكم & تراكم.r & تراكم.r & تراكم 1. & متغير \\
\hline$\Lambda / r a \cdot \pm \cdot / 11^{a}$ & $\wedge / \sim q \cdot \pm \cdot / \cdot \wedge^{\mathrm{a}}$ & $\wedge / ৭ \Lambda \cdot \pm \cdot / \cdot \wedge^{\mathrm{a}}$ & $\Lambda / F \wedge \Delta \pm \cdot / \cdot \mu^{a}$ & بار غذادهى \\
\hline$\Lambda / \Delta 1 \cdot \pm \cdot / \cdot r^{\mathrm{a}}$ & $\Lambda / q 4 \cdot \pm \cdot / \cdot r^{\mathrm{a}}$ & $a / r \Delta \Delta \pm \cdot /\left.\cdot \cdot\right|^{\mathrm{a}}$ & $\Lambda / v \Delta \Delta \pm \cdot / \cdot 19^{a}$ & Fار غذادهى \\
\hline
\end{tabular}

جدول Y - تغييرات (ميانخين土 انحراف معيار) هدايت الكتريكى (ميكروزيمنس بر سانتىمتر مربع) در تراكم و دفعات غذادهى مختلف.

Table 7. Changes (mean $\pm \mathrm{SD}$ ) in the electrical conductivity $\left(\mu \mathrm{Siemens} / \mathrm{cm}^{2}\right)$ in different density and feeding.

\begin{tabular}{|c|c|c|c|c|}
\hline \multicolumn{5}{|c|}{ times } \\
\hline تراكم •ع & تراكم.r & تراكم +r & تراكم • 1 & متغير \\
\hline $\mid F r \Delta / \cdot \pm \Lambda / F q^{a}$ & $|f \cdot r / \cdot \pm| r / V^{a}$ & $|F| V / \Delta \pm \mid r / \cdot V^{a}$ & $|F| q / \Delta \pm r / \Delta f^{a}$ & rارغذادهى \\
\hline $1099 / \Delta \pm 19 / .9^{a}$ & $|99 \mathrm{~V} / \cdot \pm 9 \cdot / 1|^{\mathrm{a}}$ & $19 \cdot \Delta / \Delta \pm r r / r r^{a}$ & $1 / V r \Delta \pm \cdot / \cdot q r^{\mathrm{a}}$ & أبار غذادهى \\
\hline
\end{tabular}

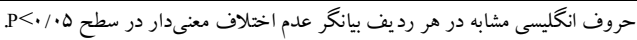

Same letters in the same row indicate a non-significant difference $\mathrm{P}<0.05$.

در تحقيق حاضر، افز ايش دفعات غـذادهى از Y بـه F بـار در شـبانه -

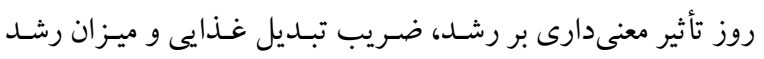

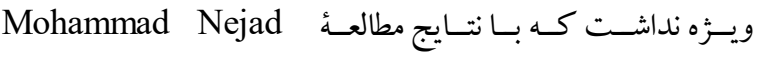
Shamoushaki همكاران (2009) دربارهٔ تيلاييا مطابقت دارد و بهنظـر مـىرسـ كـه

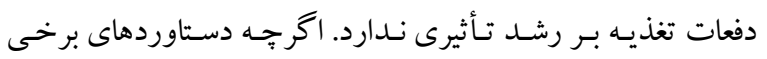

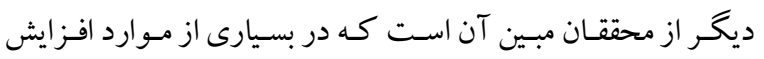
دفعات غذادهى، افزايش يذيرش غـذا و مقـدار رشـــ مـاهى را نشـان مسدهـ (Chua \& Teng, 1987; Kayano et al., 1993).


غذا و درنتيجه بازدهى و ضريب تبديل غذايى بهبود مسىيابـد. بعضى مطالعات نشان دادهاند ماهيانى كه در زمـان ترجيحىى تغذيـهُ خـود و

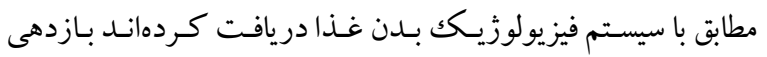
رشـد بهتـرى داشتند (Bolliet et al., 2001). فا كتورهـاى خـونى

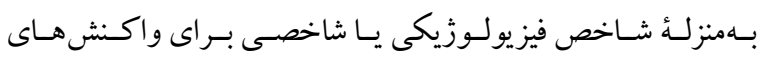
استرسزا نسبت به تغييرات درونى بدن و نيز وضعيت سـلامتى مـاهى است (Cataldi et al., 1998; Diwan \& Krishnan, 2011 . هماتوكريت خون بهمنزله شاخصى مهم و رايسج در تعيسين سـلامت و

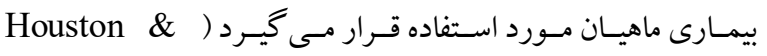
Rupert, 1997 (.). براساس برخى مطالعات تحت تأثير اسـترسهـاى فيزيكى ميز ان هماتو كريت در ماهى افز ايش مسىيابـ ( Barton et
Berg et al., 1996; Baskerville-Brides \& Kling, ) دهـ 2000; Ellis et al., 2002 يرورى نياز به تعادل بين سرعت رشد ماهى و اسـتفاده بهينـه از غـذاى فراهمشـده اسـت (El-Saidy et al., 2009). زمـانى كه مـاهى بـا مقـدارى غـذاى بـا كيفيـت بـالا و مناسـب تغذيـه شـود، رشـدى كـه هدف برورش دهنده است، بهدست خو اهد آمـــ زيـرا ميـزان غـذا بـهـ

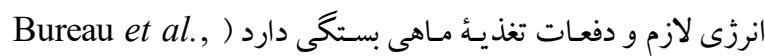
2006). غذادهى مناسب باعث افزايش رشد ماهى مسىشـود و ميـزان ضـايعات غــايى را بـه حـــاقل مسىرسـاند و تغييـر در انــازهُ مـاهى



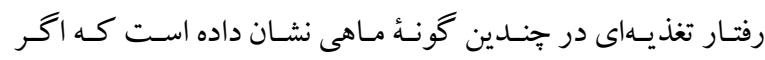
دفعات غذادهى مطابق بـا ريـتم طبيعى تغذيـه باشـــ، باعـث افزايش

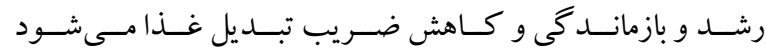
وBooth.(Mohammad Nejad Shamoushaki, 2012) همكاران (2008) بيان كردنـد كـه يـك تـا جهار وعـده غـذايى در


مــاهى آزادو Pagrus auratus داشــــ باشـــ. Johansen و

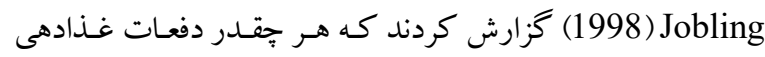
در روز بيشتر شود، فعاليت شـناى مـاهى افزايش مسىيابــ و درنتيجـه مصرف انرزى بيشتر و مقدار رشد كمتر مسىشـود. بنسابراين، بـالاترين رشد در دفعات تغذيهاى كم رخ مىدهد (Tevis et al., 1992). 


\section{REFERENCES}

Allen, K.O. 1974. Effects of stocking density and water exchange rate on growth and survival of channel catfish (Ictalurus puntatus) in circular tanks. Aquacu. 4: 29-39.

Andrews, J.W. and Page, J.W. 1975. The effect of frequency of feeding on culture of catfish. - Trans. Am. Fish. Soc. 105: 317-321.

Barcellos, L.J., Kreutz, L.C., de Souza, C., Rodrigues, L.B., Fioreze, I., Quevedo, R.M., Cericato, L., Soso, A.B., Fagundes, M., Conrad, J., Lacerda, L.A. and Terra, S. 2004. Hematological changes in jundia (Rhamdia quelen Quoy and Gaimard Pimelodidae) after acute and chronic stress caused by usual aquaculture management, with emphasis on immune suppressive effects. - Aquacu. 237: 229-236.

Barton, B.A., Weiner, G.S. and Schreck, C.B. 1985. Effect of prior acid exposure on physiological responses of juvenile rainbow trout (Salmo gairdnen) to acute handling stress. - Can. J. Fish. Aquat. Sci. 42: 710-717

Baskerville-Brides, B. and Kling, L.J. 2000. Larval culture of Atlantic cod (Gadus morhua) at high stocking densities. - Aquacu. 181: 61-69.

Bayunova, L., Barannikova, I. and Semenkova, T. 2002. Sturgeon stress reaction in aquaculture. - Appl. Ichthyol. 18: 397-404.

Berg, A.V., Sigholt, T., Seland, A. and Daniesberg, A. 1996. Effect of stocking density, oxygen level, light regime and swimming velocity on the incidence of sexual maturation an adult Atlantic salmon (Salmo salar). - Aquaculture 143: 43-59.

Björnsson, B. and Ólafsdóttir, S.R. 2006. Effects of water quality and stocking density on growth performance of juvenile cod (Gadus morhua). ICES J. Mar. Sci. 63: 326-334.

Bolliet, V., Azzadi, V. and Boujard, T. 2001. Effects of feeding time on feed intake and growth. In: Houlihan, D., Boujard, T., Jobling, M. (Eds), food intake in fish. - Blackwell Science-cost Action 827, Oxford. pp 232-249.

Booth, M.A., Tucker, B.J., Allan, G.L. and Fielder, D. 2008. Effect of feeding regime and fish size on weight gain, feed intake and gastric evacuation in juvenile Australian snapper (Pagrus auratus). Aquacu. 282: 104-110.

Boujard, T., Gelineau, A. and Corraze, G. 1995. Time of single daily meal influences growth performance in rainbow trout (Oncorhynchus mykiss). - Aquacult. Res. 26: 341-349.

Boujard, T., Labbe, L. and Benoit, A. 2002. Feeding behavior, energy expenditure and growth of rainbow trout in relation to stocking density and food accessibility. - Aquacult. Res. 256: 156-162.

Bureau, D.P., Hua, K. and Cho, C.Y. 2006. Effects of feeding level on growth and nutrient eposition in rainbow trout (Oncorhynchus mykiss) growing from 150-600 g. - Aquacult. Res. 37: 1090-1098.

Cataldi, E., Di Marco, P., Mandich, A. and Cataudella, S. 1998. Serum parameters of Adriatic sturgeon (al., 1985; Wendelaar Bonga, 1997

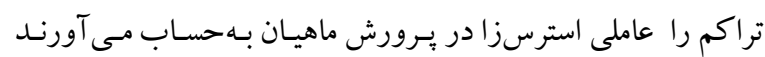

Yousif, 2002; Romsay et al., 2006; Hasanalipour )

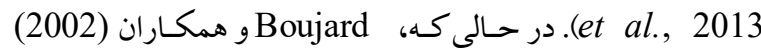

اعلام كردنــــــه تـراكم عامـل اصـلى اسـترس مـاهى نيسـت، بلكـه.

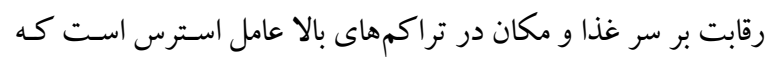

$$
\text { بر رشد تأثير منفى دارد. }
$$

عو امـل متعـددى در يافتـهـــاى محققــان در مطالعـات مربـوط بــهـ

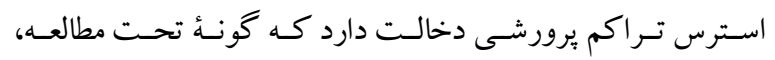





آن استرس و شدت تأثير خـذارى آن بستخى دارد ( Bayunova et

Wuertz . (al., 2002 و همكاران (2006) اسـترسز زابـودن تـراكم

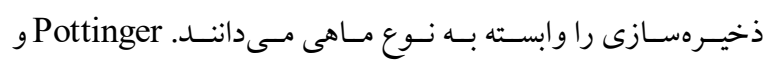

(1997) Pickering



مختلـف غـذادهى بـر شـاخص هـاى رشــ و هماتو كريـت، مسىتـوان

تـراكم • اقطعـه مـاهى در آكواريـوم بـا دو نوبـت غـذادهى در روز

جهت رشد مطلوب، بهـرهبـردارى مناسـب غـذايى و بـالابردن ميـزان

$$
\text { توليد ماهى كلمه بيشنهاد كرد. }
$$

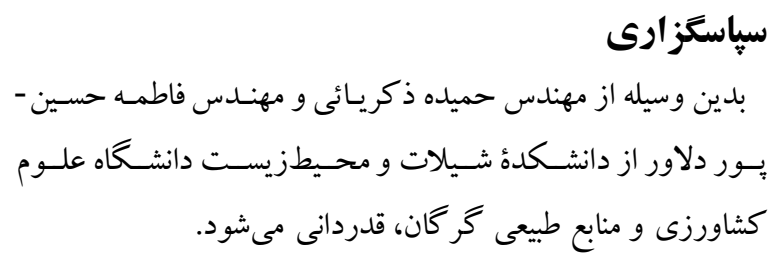


(Acipenser naccarii) effects of temperature and stress. - J. Com. Bioch. Physi. 121: 351-354.

Chua, T. and Teng, S. 1987. Effect of feeding frequency on the growth of young estuary grouper (Epinephelus tauvina) culture in floating net-cages. - Aquacu. 14: 31-47.

Chun, T.E. and Teng, S.K. 1982. Effects of food ration on growth, condition factor, food conversion efficiency and net yield of estuary grouper (Epinephelus salmoides Maxwell) cultured in floating net-cages. Aquacu. 27: 273-283.

Diwan, A.D. and Krishnan, L. 2011. Levels of cholesterol in blood serum and gonads in relation to maturation in Etroplus suratensis. - Cen. Mar. Fish. Res. Ins. Cochin. 682031: 241-245.

Dwyer, K.S., Brown, J.A., Parrish, C. and Lall, S.P. 2002. Feeding frequency affects food consumption feeding pattern and growth of juvenile yellowtail flounder (Limanda ferruginea). - Aquacu. 213: 279292.

Ellis, T., North, B., Scott, A.P., Bromage, N.R., Porter, M. and Gadd, D. 2002. The relationship between stocking density and welfare in farmed rainbow trout. - J. Fish Biol. 61: 493-531.

El-Saidy, D.M.S.D., Abo Ashour, A.M.H., El-Fiky, A.A. and Alaam, A.E. 2009. Effect of feeding frequency and stocking density on the performance of mono sex Nile tilapia in concrete tanks. - Minufiya J. Agric. Res. 34: 1027-1048.

Gokcek, K.C., Mazlum, Y. and Akyurt, I. 2008. Effects of feeding frequency on growth and survival of Himiri Barbus luteus fry under laboratory conditions. - Pakistan J. Nutr. 7: 66-69.

Hasanalipour, A., Eagderi, S., Poorbagher, H. and Bamani, M. 2013. Effects of stocking density on blood cortisol, glucose and cholesterol levels of immature Siberian sturgeon (Acipenser baerii). Turk. J. Fish Aquat. Sci. 13: 27-32.

Hasan Netaj Niazie, E., Imanpoor, M.R., Taghizadeh, V. and Zadmajid, V. 2013. Effects of density stress on growth indexes and survival rate of goldfish (Carassius auratus). - Global Veterinaria 10: 365-371.

Holm, J., Refsite, T. and Sigbjorn, S. 1990. The effect of fish density and feeding regimes on individual growth rate and mortality in rainbow trout (Oncorhynchus mykiss). - Aquacu. 89: 225-232.

Houston, A.H. and Rupert, R. 1997. Immediate response of hemoglobin system of gold fish (Cyprinus auratus) to tempera change. - Can. J. Zool. 54: 17311741.

Hung, S.S.O., Lutes, B. and Storebakken, T. 1989. Growth and feed efficiency of white sturgeon (Acipenser transmontanus) sub- rearing at different feeding rates. - Aquacu. 80: 147-153

Iguchi, K., Ogawa, K., Nagae, M. and Ito, F. 2003. The influence of rearing density on stress response and disease susceptibility of ayu (Plecoglossus altivelis). - Aquacu. 220: 515-523.

Imanpoor, M.R., Ahmadi, A.R. and Kordjazi, M. 2009. Effects of stocking density on survival and growth indices of common carp (Cyprinus carpio). - Iran. Sci. Fish. J .18: 1-9.

Imanpoor, M.R. and Roohi, Z. 2015. Influence of primalac probiotic on growth performance, blood biochemical parameters, survival and stress resistance in the Caspian roach (Rutilus rutilus) Fry. - Turk. J. Fish Aquat. Sci. 15: 917-922.

Irwin, S., Ohalloran, J. and Fitzgerald, R.D. 1999. Stocking density, growth variation in juvenile turbot (Scophthalmus maximus). - Aquacu. 178: 77-88.

Jobling, M. 1994. Fish Bioenergetics. - Chapman \& Hall, London, UK. 309 pp.

Jobling, M. 1995. Feeding of charr in relation to aquaculture. - Nord. J. Freshw. Res. 71: 102-112.

Jobling, M. and Baardvik, B.M. 1994. The influence of environmental manipulation on inter-and intraindividual variation in food acquisition and growth performance of Arctic charr (Salvelinus alpines). - J. Fish. Biol. 44: 1069-1087.

Johansen, S.J.S. and Jobling, M. 1998. The influence of feeding regime on growth and slaughter traits of cage-reared Atlantic salmon. - Aquac. Inter. 6: 1-17.

Kayano, Y., Yao, S., Yamamoto, S. and Nakagawa, H. 1993. Effects of feeding frequency on the growth and body constituents of young redspotted grouper (Epinephelus akaara). - Aquacu. 110: 271-278.

Kiabi, B.H., Abdoli, A. and Naderi, M. 1999. Status of the fish fauna in the South Caspian basin of Iran. Zool. Middle East 18: 57-65.

Kristiansen, T.S., Ferno, A., Holm, J.C., Privitera, L., Bakke, S. and Fosseidengen, J.E. 2004. Swimming behavior as an indicator of low growth rate and impaired welfare in Atlantic halibut (Hippoglossus hippoglossus) reared at three stocking densities. Aquacu. 230: 137-151.

Lee, S.M., Hwang, U.G. and Hwoan, S. 2000. Effects of feeding frequency and dietary moisture content on growth, body composition and gastric evacuation of juvenile Korean rock fish (Sebastes schlegeli). Aquacu. 187: 399-409.

McCarthy, I.D., Carter, C.G. and Houlihan, D.F. 1996. The effect of feeding hierarchy on individual variability in daily feeding in rainbow trout (Oncorhynchus mykiss). - J. Fish. Biol. 41: 257-263.

Mohammad Nejad Shamoushaki, M. 2012. Effect of feeding frequency on growth performances and survival of Rutilus rutilus caspicus. - J. Res. Bio. 3: 200-205.

Moradyan, H., Karimi, H., Gandomkar, H.A., Saraeian, M.R., Ertefaat, S. and Hosseinzadeh Sahafi, H. 2012. The effect of stocking density on growth parameters and survival rate of rainbow trout alevins (Oncorhynchus mykiss). - World J. Fish. Mar. Sci. 4: 480485.

North, B.P., Turnbull, J.F., Ellis, T., Porter, M.J., Migaud, H., Born, J. and Bromage, N.R. 2006. The impact of stocking density on the welfare of rainbow trout (Oncorhynchus mykiss). - Aquacu. 255: 466479.

Pottinger, T.G. and Pickering, A.D. 1997. Genetic basis to the stress response: selective breeding for stress- 
tolerant fish. In: Iwama, G.K., Pickering, A.D., Sumpter, J.P., Schreck, C.B. (Eds), fish stress and health in aquaculture. - Combridge University Press, Combridge, pp. 171-193.

Rafatnezhad, S., Falahatkar, B. and Tolouei Gilani, M.H. 2008. Effects of stocking density on haematological parameters, growth and fin erosion of great sturgeon (Huso huso) juveniles. - Aquac. Res. 39: 1506-1513.

Rahman, M.M., Verdegem, M.C.J., Nagelkerke, L.A.J., Whab, M.A. and Verreth, J.A.J. 2008. Swimming, grazing and behavior of rohu (Labeo rohita) and common carp (Cyprinus carpio) in tanks under fed and non-fed conditions. - Appl. Anim. Behav. Sci. 113: 255-264.

Rahman, M.M., Kadowaki, S., Balcombe, S.R. and Wahab, M.A. 2010. Common carp (Cyprinus carpio) alters its feeding niche in response to changing food resources: direct observations in simulated ponds. Ecol. Res. 25: 303-309.

Rahman, M.M. and Verdegem, M.C.J. 2010. Effects of intra-and interspecific competition on diet, growth and behavior of Labeo calbasu and Cirrhinus cirrhosis. - App. Anim. Behav. Sci. 128: 103-108.

Romsay, J.M., Feist, G.W., Varga, Z.M., Westerfield, M., Kent, M.L. and Schreck, C.B. 2006. Whole-body cortisol is an indicator of crowding stress in adult zebrafish (Danio rerio). Aquacu. 258: 565-574.

Rowland, S.J., Mifsud, C.H., Nixon, M. and Boyd, P. 2006. Effects of stocking density on the performance of the Australian freshwater silver perch (Bidynus bidynus) in cages. - Aquacu., 253: 301-308.

Ruohenen, K., Vielma, J. and Grove, D.J. 1998. Effects of feeding frequency on growth and food utilization of rainbow trout (Oncorhynchus mykiss) fed low-fat herring or dry pellets. - Aquacu. 165: 111-121.

Schram, E., Van der Heul, J.W., Kamstra, A. and Verdegem, M.C.J. 2006. Stocking density-dependent growth of Dover sole (Solea solea). - Aquacu. 252: 339-347.

Sheare, K.D. 1994. Factor affecting the promixate compotion of culture fishes emphasis on salmonids. Aquacu. 119: 63-68.

Tevis, N., Klaoudatos, S. and Conides, A. 1992. Food conversion budget in sea bass (Dicentrachus labrax) fingerlings under two different feeding frequency patern. - Aquacu. 101: 293-304.

Wallace, J.C., Kolbeinshaven, A.G. and Reinsnes, T.G. 1988. The effects of stocking density on early growth in Arctic charr (Salvelinus alpinus). - Aquacu. 73: 101-110.

Wang, Y., Kong, L.J., Li, K. and Bureau, D.P. 2007. Effects of feeding frequency and ration level on growth, feed utilization and nitrogen waste output of cuneate drum (Nibea miichthioides) reared in net pens. - Aquacu. 271: 350-356.

Wendelaar Bonga, S.E. 1997. The stress response in fish. - Physio. Rev. 77: 591-625.

Woods, C.M.C. 2003. Effect of stocking density and gender segregation in the seahorse (Hippocampus abdominals). - Aquacu. 218: 167-176.
Wuertz, S., Lutz, I., Gessner, J., Loeschau, P., Hogans, B., Kirschbaun, F. and Kloas, W. 2006. The influence of rearing density as environmental stressor on cortisol response of shortnose sturgeon (Acipenser brevirostrum). - J. App. Ichthiol. 22: 269-273.

Yousif, O.M. 2002. The effects of stocking density, water exchange rate, feeding frequency and grading on size hierarchy development in juvenile Nile tilapia (Oreochromis niloticus). - Emirates J. Agri. Sci. 14: 45-53.

$$
* * * * *
$$

How to cite this article:

Imanpoor, M.R., Nemati, M., Afshar, H. and Roohi, Z. 2018. Effects of stocking density and feeding frequency on the growth parameters and hematocrit of the Rutilus rutilus caspicus juvenile. - Nova Biologica Rep. 5: 45-52.



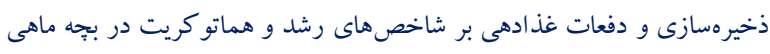

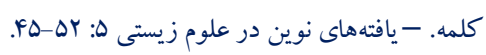

